\title{
IMPLICAÇÕES DA PANDEMIA NA EDUCAÇÃO: O TRABALHO DO GESTOR ESCOLAR NA REDE PRIVADA DE ENSINO
}

\author{
PANDEMIC'S IMPLICATIONS ON EDUCATION: THE TASK OF THE PRIVATE \\ SCHOOL MANAGER
}

\author{
José Wellington Freire Rodrigues ${ }^{1}$ \\ Tatiane Bantim da Cruz ${ }^{2}$
}

RESUMO: A pandemia ocasionou mudanças impactantes na sociedade, obrigando as pessoas a manterem-se distantes e isoladas, provocando a paralisação de alguns setores e alterações no funcionamento de outros, como é o caso da educação. Diante dessa realidade, este trabalho tem como foco a atuação dos gestores frente ao cenário da pandemia. Para refletir sobre tal atuação, tem-se como objetivo geral: investigar os impactos da pandemia no trabalho da gestão escolar da rede privada de educação da cidade de Araripe-CE. E como objetivo específico, busca-se compreender o trabalho do gestor mediante o formato de ensino remoto. Para isso, definiu-se como metodologia: a abordagem qualitativa, com pesquisa bibliográfica e também pesquisa de campo, a fim de relacionar teoria e prática. Os autores selecionados para a construção deste trabalho e para a análise dos dados são: Rodrigues (2020), Kenski (2003), Peres (2020), Saraiva; Travessini, Lockmann (2020), dentre outros. Pôde-se concluir que os gestores têm papel fundamental na articulação e execução de boas práticas que possibilitem um bom rendimento da instituição, principalmente em um cenário de crise na saúde pública.

Palavras-chave: Gestão.Pandemia. Educação.

ABSTRACT: The pandemic has caused meaningful changes in society, compelling people to keep distant and isolated, forcing certain sectors' stoppage, and bringing alterations into the routines of other ones, such as education. Facing this reality, this paper focuses on

\footnotetext{
I Especialista em Gestão Escolar pelo curso de Pós-Graduação Lato Sensu, da Universidade Regional do Cariri - URCA, possui graduação em Pedagogia. É membro do Grupo de Estudos e Pesquisas em Ensino das Artes Visuais na Educação Infantil e nos anos iniciais do Ensino Fundamental - GEPEANAINF. Atualmente é professor dos anos iniciais do ensino fundamental. Desenvolve estudos na área da Gestão, Administração Educacional e Trabalho docente. Lattes: http://lattes.cnpq.br/421645892670oori.Orcid: https://orcid.org/oooo-ooo2-5389-8606. E-mail: Wellington-ff@hotmail.com.

${ }_{2}$ Mestre pelo Programa de Mestrado Profissional em Educação, da Universidade Regional do Cariri, é especialista em Metodologia de Ensino e Docência do Ensino Superior e possui graduação em Pedagogia. É integrante do Laboratório de estudos e pesquisas sobre Gênero, Educação, Sexualidade e Diferenças LEGRAR. No momento, também atua como professora substituta da Universidade Regional do Cariri, lecionando disciplinas ligadas a história da educação e pesquisa. E desenvolve estudos na área de educação, gênero, identidade e diferença. Orcid: https://orcid.org/oooo-ooo2-3685-322X. E- mail: tatianebantim@hotmail.com.
} 
managers' performances facing this pandemic scenario. Reflecting upon such performances, the general goal is to investigate the pandemic's impact on the management work in private schools from Araripe - CE. And as a specific goal, the aim is to comprehend managers' work regarding remote teaching. To do so, a qualitative approach along with bibliographic and field research to relate theory and practice were defined as methodology. The authors selected for the construction of this research as well as for data analysis are Rodrigues (2020), Kenski (2003), Peres (2020), Saraiva; Travessini, Lockmann (2020), among others. It was possible to conclude that managers play a pivotal role in the articulation and execution of good ractices that enable good institutional input, mainly in a scenario of public health crisis.

Keywords: Management. Pandemic. Education.

\section{INTRODUÇÃO}

A pandemia do novo Corona vírus, causada pelo agente SARS-CoV2 identificado inicialmente em Wuhan, na China, ao final de 2019 e aqui no Brasil em fevereiro de 2020, dando início a infecção letal a vida humana. Para frear os impactos desta doença devastadora as autoridades do sistema de saúde com base nas orientações da OMS, proferiram medidas profiláticas; lavar bem as mãos, utilizar álcool gel, máscara etc. As autoridades estaduais seguindo estes mesmos protocolos decretaram medidas de isolamento social, distanciamento social e, em casos mais severos como as cidades que decretaram calamidade pública, optaram por Lockdown e toques de recolher.

Essas medidas impactam diretamente todas as esferas societárias, pois a contenção da infecção necessita da paralisação em massa das atividades consideradas não essenciais a fim de diminuir o fluxo e o contato de pessoas. Saúde, comercio, economia, lazer, educação, indústria dentre outros foram afetados. A educação é um dos setores afetados, pois o funcionamento das escolas demanda quantidades significativas de pessoas, por um longo período de tempo, com salas muitas vezes superlotadas. Então, para se prosseguir com as aulas e atividades educativas, tanto em escolas públicas quanto privadas, adotaram-se o modelo de aulas remotas, segundo decreto do Ministério da Educação (MEC).

$\mathrm{O}$ uso das tecnologias digitais para fins educativos acaba, nesse contexto, ganhando força, uma vez que este é o único meio seguro e interativo de manter a comunicação em meio à pandemia.

Assim, é pertinente questionar: como tem acontecido o trabalho do gestor escolar no cenário da pandemia e com o ensino acontecendo no formato remoto?

A fim de responder essa indagação, delimitamos como objetivo geral deste trabalho: investigar os impactos da pandemia no trabalho da gestão escolar da rede privada de educação da cidade de Araripe-CE, em busca de analisar os impactos da pandemia no trabalho dos gestores da referida cidade, como objetivo especifico buscamos compreender o trabalho do gestor mediante ao formato de ensino remoto, tendo em vista o novo contexto educacional mediado pelas tecnologias.

A metodologia aplicada para construção deste estudo é de abordagem qualitativa, com uso de pesquisa bibliográfica. E para coleta de dados foi realizado uma pesquisa de 
campo com aplicação de questionários, no formato online, construído e enviado pelo Google forms, permitindo aos participantes responderem de acordo com suas disponibilidades.

Para dialogar com os resultados obtidos e construir o referencial deste trabalho foram selecionados artigos do Google acadêmico dos quais constam aqui autores como Kenski (2003), Peres (2020), Saraiva; Travessini; Lockmann (2020), Rodrigues (2020), dentre outros.

Este trabalho justifica-se, pois, pelo impacto sanitário provocado pelo coronavírus, uma vez que essa infecção no que concerne à educação escolar provoca desafios na estrutura do sistema educativo, com a paralização das atividades presenciais, o ensino remoto emergencial tornou-se a opção viável para todas as instituições nas mais variadas etapas e modalidades da educação, assim sendo, é necessário entender que o papel do gestor neste cenário é fundamental, que este profissional, organiza, auxilia e direciona atividades para que nesta crise, os impactos sejam menores.

\section{GESTÃO ESCOLAR NO CONTEXTO DA PANDEMIA: REFLEXÕES SOBRE O ENSINO REMOTO E À DISTÂNCIA}

É certo que no atual cenário de Pandemia do novo Coronavírus, a sociedade em todos os seus seguimentos sofreu impactos devastadores, paralisação de atividades presenciais, fechamento do comércio e setores não essenciais, dentre outros. Isso denota a seriedade contagiosa que o vírus possui.

Com a crise epidemiológica de Covid-ıg, vírus identificado inicialmente na China

ao final de 2019. A sociedade teve que encontrar meios de se ajustar a nova realidade, os diversos setores adequaram-se para proteger a vida humana, o isolamento social e o distanciamento social impactaram diretamente na educação, comércio, economia, cultura e etc. principalmente o sistema educacional como versam as autoras Saraiva; Traversini e Lockmann (2020):

Medidas de isolamento social para reduzir a contaminação são adotadas ao redor do mundo, com maior ou menor rigidez. Quase sempre, as primeiras instituições alcançadas por essas medidas são as educacionais, ambientes que mantêm um grande número de indivíduos confinados juntos por longos períodos. (p. o2)

Nesta direção, vemos o quão letal é este vírus, a imensa probabilidade de contágio em ambientes fechados e com fluxo grande pessoas, como as escolas. Com isso o gestor teve que se reorganizar para dar continuidade ao seu trabalho em meio a uma crise na saúde pública, este profissional teve que se articular para o bom funcionamento da educação num sistema remoto ${ }^{3}$. O planejamento é peça chave para que esse novo formato de ensino aconteça. Este que deve ocorrer em consonância com gestores e docentes, para um trabalho efetivamente harmônico.

As tecnologias digitais da informação e comunicação (TDIC) são ferramentas essenciais na construção de estratégias no cenário Pandêmico, tornando-se meios necessários na comunicação, na interatividade e na troca de informações, auxiliando corpo docente e discente, em uma aprendizagem colaborativa, através das mídias audiovisuais e

${ }^{3}$ Com a Pandemia do novo Coronavírus, o ensino remoto foi adotado, uma espécie de educação à distância onde os alunos estudam em casa, tem aulas e atividades domiciliares em plataformas digitais online. 
das plataformas de ensino, as aulas agora acorrem virtualmente segundo medidas decretadas por órgãos responsáveis pelo sistema de ensino em consonância com exigências sanitárias.

Dado o contexto da Pandemia de Covid-19, um dos setores mais atingidos, como já mencionado, foi à educação, pois as instituições educativas aglomeram em seus espaços numerosas quantidades de alunos, então a paralisação das atividades presenciais foram uma das maneiras de conter a contaminação do vírus, levando a sociedade a se reorganizar, utilizando o ensino remoto e a educação à distância (EAD), medida emergencial defendida pela UNESCO, devido à paralisação das escolas em diversos países do globo, assim:

\begin{abstract}
A Unesco (Organização das Nações Unidas para a Educação, Ciência e Cultura) lançou nesta quinta-feira uma coalizão mundial para assegurar a educação à distância dos mais de 1,5 bilhão de alunos de 165 países afetados pelo fechamento de escolas devido à pandemia do coronavírus. (UNESCO ANUNCIA, 2020, n.p.)
\end{abstract}

Este fato mostra a importância do ensino remoto para amenizar os impactos dessa infecção brutal na saúde humana. Mais uma vez é necessário refletir sobre o papel do gestor em meio a essa crise. Destacar que ensino a distância é um modelo de educação feito em formato digital, acessível em plataformas de instituições pela internet, estas possuem um planejamento subjacente as suas práticas, mediada pelas Tecnologias Digitais de Informação e Comunicação (TDIC), como ressalta Rodrigues (2020), já o ensino remoto é uma medida emergencial, onde os professores produzem conteúdos e gravam vídeo-aulas, utilizando diversas plataformas para transmissão.

Assim, esta medida emergencial, advoga a necessidade de se utilizar as plataformas digitais em meio à crise de saúde pública, como asseveram as autoras:

Que as atividades presenciais deveriam ser transpostas, por meio de ferramentas digitais, para um modelo de educação remota enquanto durasse a crise sanitária. Tal decisão recebeu, inclusive, suporte legal do Ministério da Educação (MEC). (SARAIVA; TRAVERSSINI e LOCKMANN, 2020, p. 03)

A medida adotada pelo MEC estabelece provisoriamente o uso de plataformas digitais de forma emergencial, para todos os níveis e modalidades do sistema de ensino, neste viés, em âmbito mais restrito o Conselho Estadual de Educação do Ceará - CEE/CE, estabelece através do parecer $\mathrm{n}^{\mathrm{o}}: 0205 / 2020$, orientações para as instituições educativas vinculadas ao sistema estadual de educação, tanto as escolas públicas quanto as privadas, regulamenta "à utilização de atividades remotas, enquanto durarem as determinações de isolamento social" (CEE/CE, 2020, p. or).

As atividades em formato remoto acontecerão a fim de amenizar os impactos provocados pela pandemia, onde as instituições devem se articular para que seja possível esse novo formato educativo, sendo cabível a administração de cada um a autonomia para prosseguir com as atividades remotas.

Outro fator importante a ser considerado sobre o uso das tecnologias e plataformas digitais no ensino, é que essa medida emergencial, desencadeou nos docentes e gestores receios em utilizar plataformas digitais e promover aulas no formato virtual, pois muitos não possuem preparo exigido para o manuseio destes aparatos tecnológicos, como ressalta Peres (2020): 
O gestor, além da constante preocupação com as melhorias dos índices educacionais, passou a preocupar-se com a transposição das aulas presenciais para aulas em ambientes virtuais, administrando com isso, o seu próprio despreparo, e também, o despreparo dos docentes para o uso de ferramentas tecnológicas para aulas virtuais $[\ldots]$ (p. 24)

Estes profissionais encontram dificuldades na execução das tarefas agora em formato remoto, outro agravante levado em consideração são os índices do aluno que refletem diretamente nos índices da instituição de ensino, que no formato digital através do ensino remoto a qualidade da educação pode cair, por fatores como o mau uso das plataformas, por exemplo.

Este profissional deve mediar à comunicação e o planejamento para que as aulas no formato virtual sejam desempenhadas eficazmente. Mas que em meio a tantos conflitos surgem dificuldades e desafios na efetivação de um bom trabalho, muitos gestores buscam por uma gestão efetivamente democrático, e neste cenário pandêmico, as exigências do sistema educacional por índices desejáveis geram conflito e dificuldade, Peres (2020) discute:

Diante disto, fica evidente a importância do gestor escolar no desempenho de suas funções, entretanto, quando o cenário já se configurava como aparentemente estável, diante de conquistas concretas no processo de gestão escolar, esse contexto se altera radicalmente com as novas demandas causadas pela chegada da pandemia no Brasil. (p.23)

É perceptível que a Pandemia, acarretou ao trabalho de vários profissionais desafios na execução de suas funções, atingindo principalmente para o sistema educacional, adaptarse as novas exigências que o contexto da Pandemia trouxe foi uma solução possível com o ensino remoto, e o uso de tecnologias e plataformas como o Google meet, Google Classroon, apps, dentre outras ferramentas.

É certo que esta crise de saúde publica, acarretada pelo Covid-ı, deixará sequelas na vida das pessoas, na sociedade e seus diversos segmentos, e principalmente na educação, como declara Ely (2020, n.p):

Há consenso entre especialistas que o ensino remoto não substitui o presencial, mas, ao menos, contribui para minimizar os danos causados pela suspensão das aulas. Para o diretor de políticas públicas do Todos Pela Educação, Olavo Nogueira Filho, o afastamento do ambiente escolar deixará sequelas que precisam ser amenizadas mesmo [a] distância.

As marcas deixadas na educação escolar, segundo Alves (2020), principalmente na vida dos educandos, denotam problemas que podem desenvolver-se na sua aprendizagem e posteriormente na sua saúde mental, emocional e da convivência social. Os gestores em meio ao seu trabalho exaustivo para que a educação continue também são assombrados por esses fatores, hora tem que trabalhar excessivamente com atividades remotas (articulandose com alunos e professores, para dar continuidade ao processo de ensino aprendizagem), hora tem que cuidar de si próprios em meio a pandemia (também, de sua saúde física e mental, e dos encargos emocionais desencadeados por essa crise sanitária).

De toda e qualquer forma esta é o dito "novo normal" que irá perdurar enquanto não houver uma vacina disponível capaz de assegurar à volta as atividades cotidianas, por 
esta razão, as medidas de profilaxia, o isolamento social e o ensino remoto são as melhores ferramentas no combate a disseminação do contágio, e para isso o papel de planejamento, articulação e liderança do gestor é fundamental.

\section{PROCEDIMENTOS METODOLÓGICOS}

Para se chegar a todos os resultados aqui contidos, este artigo passou por uma série de passos e processos, constituindo-se de uma abordagem qualitativa que permite ao pesquisador conhecer o fenômeno estudado e interpretá-lo, quanto aos objetivos propostos esta pesquisa caracteriza-se como exploratória, por se tratar de um assunto novo pouco abordado, como também argumenta Gonsalves (2003, p. 65), a pesquisa exploratória "é aquela que se caracteriza pelo desenvolvimento e esclarecimento de ideias, com objetivo de fornecer uma visão panorâmica, uma primeira aproximação a um determinado fenômeno que é pouco explorado".

A pesquisa bibliográfica, um dos componentes deste trabalho é basilar na preparação de qualquer discussão referente ao assunto estudado como asseveram Marconi e Lakatos (2003, p. 158), que "A pesquisa bibliográfica é um apanhado geral sobre os principais trabalhos já realizados, revestidos de importância, por serem capazes de fornecer dados atuais e relevantes relacionados com o tema".

A despeito da pesquisa de campo, pode-se dizer que esta é fundamental no conhecimento direto com os fatos estudados, permite uma maior aproximação entre pesquisador e pesquisado. Sobre a coleta de dados, foram utilizados questionários através da plataforma online do Google Forms, onde os dois gestores convidados a responder o questionário, aqui citados responderam virtualmente o questionário, isentando-os de uma entrevista presencial, possibilitando a estes responderem de acordo com seu tempo e disponibilidade e respeitando os protocolos de segurança sanitária.

Os sujeitos perscrutados responderam ao questionário via Google forms entre os dias 05 e 07 de fevereiro de 202I, permitindo que suas respostas instantaneamente chegassem até o e-mail de origem do questionário para análise dos dados. $\mathrm{Na}$ tabulação das respostas obtidas, os gestores em questão tiveram suas identidades preservadas por motivos éticos e por respeito as suas decisões de não se identificarem.

Os gestores atuam na mesma escola da rede privada de ensino do município de Araripe-CE, respectivamente os gestores desempenham trabalho nas etapas da Educação Infantil e anos iniciais e finais do Ensino Fundamental. A escolha destes profissionais para a pesquisa, reflete a necessidade de se conhecer também a perspectiva escolar privada em relação aos efeitos da pandemia do novo Coronavírus, neste viés, pois no que tange a estrutura escolar da rede privada a questão econômica com a paralização das aulas presenciais é o principal problema enfrentado pela administração da instituição.

\section{O CAMPO DA PESQUISA: A INSTITUIÇÃO ESCOLAR E SEUS ASPECTOS}

Para a construção deste trabalho, além da pesquisa bibliográfica, foi realizada uma pesquisa de campo a fim de dialogar teoria e prática neste cenário pandêmico cujo qual assola as esferas societárias, o objeto de estudo então é uma escola da rede privada de ensino do município de Araripe-CE. 
A referida Escola da rede particular de ensino é uma instituição educativa que abrange os seguintes níveis da educação básica: educação infantil; anos iniciais do ensino fundamental e anos finais do ensino fundamental. Conta com docentes graduados nas diversas áreas do conhecimento e professores auxiliares na educação infantil. Atende a uma clientela de 80 alunos, onde o funcionamento é apenas em turno matutino.

Vale ressaltar que é destacado aqui o horário do funcionamento da instituição mesmo num período pandêmico, pois a escola seguindo as orientações sanitárias e por contar com um número pequeno de alunos se enquadra nos critérios para a reabertura do ano letivo que ocorreu no dia i8 de janeiro de 2021.

A Estrutura física da escola é distribuída em dois prédios separados, um atende os anos iniciais e finais do ensino fundamental e o outro atende as turmas da educação infantil. Contando com amplo espaço para jogos e atividades, biblioteca e sala de vídeo.

A administração do recinto é organizada entre quatro gestores; diretora, dois coordenadores e um administrador financeiro.

\section{I OS SUJEITOS DA PESQUISA: FORMAÇÃO E TEMPO DE ATUAÇÃO NO CARGO}

Levando em consideração todos os dados mencionados no item anterior, sobre estrutura física e administrativa da instituição, fez-se necessário conhecer a perspectiva dos gestores sobre o ensino remoto e o quão impactante tem sido a educação escolar nesta crise epidemiológica, para tal tomamos como empréstimo as respostas dos sujeitos perscrutados que são coordenadores da instituição e que responderam a um questionário virtual através de plataforma digital, cujo qual dispensa a presença física mantendo as recomendações do distanciamento social e pela facilidade de obtenção e observação das respostas coletadas.

Assim, os dois gestores atuantes na mesma instituição escolar receberão pseudônimos para preservar suas identidades mediante questões éticas, haja vista que as respostas contidas aqui expressam a verdade sobre as indagações levantadas sobre a temática aqui exposta. Neste contexto a tabela a seguir expõe as características concernentes a cada gestor, formação inicial e tempo de atuação na gestão escolar

Tabela I - formação inicial e tempo de serviço na função de gestor

\begin{tabular}{|c|c|c|}
\hline NOME FICTÍCIO & FORMAÇÃO & TEMPO DE ATUAÇÃO \\
\hline Zeus & Educação Física & I ano \\
\hline Hércules & História & 5 anos \\
\hline
\end{tabular}

Fonte: elaborada pelos autores

O cargo de gestor escolar concedido aos docentes é uma função que demanda comprometimento com a rotina escolar e boa organização dos aspectos e fatores da 
instituição, que por este motivo necessita de profissionais engajados e com certo grau de experiência na dinâmica escolar, assim subtende-se que os professores seguem a carreira docente e que a função de gestor lhes é atribuída posteriormente.

Ao se avaliar os dados coletados, percebe-se que o gestor Hércules possui um período consideravelmente longo de atuação no cargo de gestor, o que pode denotar uma vasta experiência na dinâmica escolar e nos aspectos administrativos e pedagógicos da instituição, enquanto Zeus aparenta ser novo nesta atribuição pedagógica, sendo possível entender que estando a pouco tempo numa função como esta, o gestor ainda deve apreender muito sobre os encargos desta atividade. Pois o gestor tem a função primordial de organizar, deliberar e ser democrático nas decisões assim:

\begin{abstract}
$\mathrm{Na}$ escola, o gestor, é o responsável pela organização e administração das relações e do trabalho pedagógico. É quem deve articular os processos formativos da escola em consonância com a realidade social, sendo, portanto, necessário a este profissional não apenas o domínio técnico de procedimentos administrativos, mas também a capacidade de diálogo com seus pares e uma clara percepção do contexto social e das inovações exigidas à escola. (OGAWA e FILIPAK, 2013, p.95)
\end{abstract}

É possível perceber então, que a função do gestor é multifacetada, e que este profissional deve estar articulado e aberto ao diálogo, ter uma boa noção dos processos do desenvolvimento do sistema educacional e dos aspectos formais administrativos da instituição, muitas vezes a sua formação e o tempo de atuação no cargo são fundamentais no sucesso destes aspectos, porém, um bom trabalho do gestor não está criteriosamente ligado a estes fatores, pode-se haver um bom trabalho e desempenho destas funções sem estar a muito tempo no cargo e sem ter uma formação especifica para ocupação de tal, pois as noções e experiências da gestão são construções gradativas.

A lei de Diretrizes e Bases da Educação Nacional LDBEN - Lei 9.394/1996 declara no Art. 64 que a administração das instituições de ensino, sua inspeção, supervisão e orientação educacional ficam a cargo dos profissionais graduados em cursos de pedagogia ou com pós-graduação na área. Apesar dos gestores mostrados não apresentarem estas características apontadas pela $\mathrm{LDB} / 1996$, isso não interfere na efetivação de uma boa gestão com vistas à construção democrática do ensino.

\title{
4.2 DIFICULDADES DA GESTÃO NA PANDEMIA DE COVID-ı9
}

A pandemia do novo coronavírus trouxe consequências catastróficas para a vida humana e para os diversos seguimentos da sociedade, um dos setores afetados foi o sistema de ensino, pois as instituições educativas agregam em seus recintos uma quantidade numerosa de alunos e profissionais, assim a paralisação de atividades presenciais foi uma medida de contenção da infecção desta doença, haja vista o alto nível de contaminação que poderia acontecer em um local que abriga uma parcela considerável de alunos.

Assim, o papel do gestor neste cenário foi vital para a continuidade das atividades escolares, agora em modalidade remota. O gestor teve que se reinventar, planejar e organizar meios que possibilitassem o desenvolvimento dessas atividades remotamente. Considerando que estas atividades devem estar em consonância com professores e a comunidade escolar, para que seja possível o sucesso escolar em meio a uma crise de saúde 
pública, indagamos os gestores a discorrer sobre como tem sido o seu papel mediante a crise do novo coronavírus, foram obtidas as seguintes respostas apresentadas na tabela abaixo

Tabela 2 - Dificuldades da gestão no cenário da pandemia de Covid-19

\begin{tabular}{|l|l|}
\hline NOME & RESPOSTA \\
\hline Zeus & $\begin{array}{l}\text { Lidar com o novo, lidar com a resistência de muitos pais que não queriam } \\
\text { aprender a manusear novas ferramentas tecnológicas e lidar com problemas } \\
\text { psicológicos de alunos, pais e professores. }\end{array}$ \\
\hline Hércules & $\begin{array}{l}\text { O coordenador pedagógico foi o personagem da educação mais afetado } \\
\text { durante essa pandemia, pois teve que provar com eficiência e maestria, a } \\
\text { importância do seu trabalho frente a inúmeras incertezas. Muitas vezes sem } \\
\text { recursos financeiros ou apoio técnico e tecnológico precisou assegurar um } \\
\text { ensino de qualidade. Teve que solucionar problemas em curto prazo, } \\
\text { amparar sua instituição, sem deixar de lado o suporte necessário aos } \\
\text { professores, educandos e comunidade escolar como um todo. Ele teve que } \\
\text { se reinventar, aprimorar suas técnicas pedagógicas e expandir seu } \\
\text { conhecimento tecnológico. Capacitar professores, buscar mecanismos } \\
\text { digitais, trabalhar o emocional de todos aqueles que compõem o processo de } \\
\text { ensino-aprendizagem. Coordenador teve que ampliar sua afetividade, agir } \\
\text { com empatia e resiliência, servir de válvula de escape e assegurar eficiência } \\
\text { mesmo diante da pressão, da cobrança e dos empecilhos cotidianos. }\end{array}$ \\
\hline
\end{tabular}

Fonte: Elaborada pelos autores

Ao analisar a fala dos sujeitos perscrutados é perceptível que a crise de covid-ı trouxe a sociedade desenfreadas modificações, a população está insegura, e os profissionais tiveram que reorganizar sua rotina e se adaptar ao novo formato educacional, acarretando incertezas e desafios para professores, gestores, alunos e familiares.

$\mathrm{Na}$ Fala de Zeus, é possível ver a resistência familiar ao se utilizar as plataformas digitais e aparatos tecnológicos na educação escolar, por vezes falta de preparo, pode-se entender assim, pois esta crise na saúde pública pega todos de surpresa pela sua velocidade de contaminação e alastramento. Outro aspecto bastante relevante a discussão também presente na fala de Hércules é sobre as questões emocionais, afetivas e socioemocionais.

Ainda sob a perspectiva de Hercules, pôde-se perceber os impasses e dificuldades enfrentados pelos gestores, pois, estes têm que lidar com diversas questões pertinentes ao âmbito escolar; os familiares, apoio ao corpo docente e auxilio a estes nas mídias digitais, e as características emocionais de todos afetados por essa infecção. O gestor destaca ainda que saber lidar com as situações e ter um bom diálogo é vital nessa função que se desdobra em diversas atividades. Neste sentido as autoras Saraiva, Traverssini, e Lockmann (2020) discutem que:

A educação remota vem trazendo questões e desafios para a Educação Básica e para a docência, mas, mesmo com todas as dificuldades, não se coloca em questão a paralisação dessas atividades. Insegurança, necessidade de adaptações rápidas, invasão da casa pelo trabalho e pela escola, ansiedade frente às condições sanitárias e econômicas são elementos presentes no cenário atual que vêm produzindo professores em estado de exaustão (p. 12) 
Nesta direção, fica evidente o caráter exaustivo dos gestores e professores mediante a esse formato de educação que é o ensino remoto, pois demanda, tempo, pratica, formação, informação e planejamento. Este formato que auxilia a práxis educativa permite dar continuidade ao ensino que antes ocorreria de forma presencial, assim este precisa contar com um planejamento articulado entre professores e gestores.

\subsection{OS DOCENTES E O ENSINO REMOTO}

É certo que gestores e professores tiveram que se reinventar e se adaptar a nova rotina de ensino que compreende o ensino remoto, por esse motivo é importante destacar o ensino remoto na perspectiva docente, assim perguntamos aos gestores como tem sido a receptividade dos docentes sobre o ensino remoto, como eles receberam esse novo formato de ensino? As respostas estão expressas na tabela abaixo:

Tabela 3 - Como tem sido a receptividade dos docentes no ensino remoto?

\begin{tabular}{|l|l|}
\hline NOME & RESPOSTA \\
\hline Zeus & $\begin{array}{l}\text { Assustadora para alguns. Alguns professores tiveram que se afastar } \\
\text { das atividades escolares, pois desenvolveram transtornos de } \\
\text { ansiedade que os obrigaram a deixar a escola }\end{array}$ \\
\hline Hércules & $\begin{array}{l}\text { Impactante. Devo destacar que alguns professores já dominavam e } \\
\text { aplicavam algumas técnicas do ensino híbrido em sala de aula, tais } \\
\text { como gamificação, métodos ativos e avaliações virtuais. Mas se até } \\
\text { esses tiveram seu emocional abalado, imagina aqueles que por falta } \\
\text { de iniciativa, suporte, tempo ou jeito mesmo tiveram que reformular } \\
\text { suas aulas do dia para a noite. }\end{array}$ \\
\hline
\end{tabular}

Fonte: Elaborada Pelos autores

O uso das tecnologias digitais de informação e comunicação (TDIC) são ferramentas essenciais na formação dos estudantes, pois estas tem um leque de informação infinita com facilidade de acesso em qualquer local por dispositivos móveis, um aparato tecnológico inegavelmente importante na construção do senso de pesquisa e autonomia dos estudantes, contudo, o uso das formais digitais na educação para dar aulas inteiramente via internet por aplicativos foi o que pegou muitos professores de surpresa.

É trazido na fala de ambos os sujeitos pesquisados que muitos reinventaram suas práticas e tiveram que fazer muitos ajustes, essa foi uma preocupação e medo intenso de professores, mesmo os que ainda sim detinham certo conhecimento sobre as tecnologias. Neste sentido a apropriação do manuseio dessas ferramentas para fins pedagógicos é fundamental assim define Kenski (2003):

A apropriação dessas tecnologias para fins pedagógicos requer um amplo conhecimento de suas especificidades tecnológicas e comunicacionais e que devem ser aliadas ao conhecimento profundo das metodologias de ensino e dos processos de aprendizagem (p.os).

Assim, o preparo para utilizar essas ferramentas seria essencial para o sucesso das práticas pedagógicas, todavia, tempo para preparo foi o que o corpo docente e a equipe 
gestora não tiveram, pois, o ensino remoto foi uma medida emergencial proferida pelo MEC, como forma para amenizar os impactos da pandemia.

É muito presente em ambas as falas dos sujeitos pesquisados as características emocionais dos docentes afetadas pela pandemia e por todo o caos provocado pelas mudanças repentinas de planos e de formatos de aula, professores que foram pegos de surpresa e tiveram que tomar posse da complexidade que é ministrar aulas em plataformas digitais, gerando uma dupla jornada de trabalho e a intensificação das cobranças por índices desejados e por uma qualidade equivalente a uma aula presencial.

Todos esses fatores contribuem para a exaustão dos profissionais e a precariedade das condições de trabalho e ainda afeta as competências socioemocionais, desestabilizando seu estado emocional, assim as autoras Saraiva, Traverssini, e Lockmann (2020) discutem que:

O trabalho vai além da carga horária contratada e o professor encontra-se disponível nos três turnos para responder às perguntas e tirar dúvidas. [...]. Além disso, há a necessidade de planejar as atividades, enviar, seja em formato digital ou físico, e, ainda, ter tempo para receber e corrigir as atividades realizadas pelos alunos. (p.13)

Fica evidenciada a dupla jornada de trabalho dos docentes e gestores, mesmo em período pandêmico, os gestores principalmente, pois estes devem gerir e distribuir tarefas e ainda auxiliar os professores nas demandas escolares.

\section{CONSIDERAÇÕES FINAIS}

A medida em que a pandemia avança, com altos índices de contaminação e mortalidade, fica evidente o quão letal é este vírus e o quanto a sociedade se encontra fragilizada diante de um inimigo biológico invisível, impossibilitando o trabalho de acontecer na sua forma convencional; reuniões com muitas pessoas, salas de aulas cheias, atividades que demandem um número grande de pessoas.

No tocante ao sistema educativo, o trabalho fica inviável de acontecer presencialmente, pois as instituições escolares abrigam um número considerável de pessoas, podendo tornar a propagação do vírus ainda mais rápida. $\mathrm{Na}$ escola aqui exposta, campo de estudo do presente trabalho, pôde-se perceber que a quantidade de alunos matriculados é razoavelmente pequena, por se tratar de uma escola privada de pequeno porte, todavia, não elimina os riscos de contaminação devido o contato humano em salas de aulas fechadas.

Então a saída para esta escola, assim como as milhares de escolas pelo país, foi estabelecer o ensino remoto como medida provisória para frear os impactos da contaminação e poder prosseguir com as atividades educativas em todas as modalidades e etapas da educação, tanto setor público como no privado.

O trabalho realizado com os gestores, referente as suas respostas do questionário enviado aos mesmos, foi importante para compreender esta situação e como a gestão atua neste quesito, sendo possível responder a nossa questão problema: como tem acontecido o trabalho do gestor escolar no cenário da pandemia? Onde as repostas foram obtidas e expressas neste trabalho em formato de tabela. Foi possível observar na fala de cada gestor as dificuldades neste cenário pandêmico e como estas dificuldades se agravam ainda mais com o ensino remoto. 
Em busca de entender esta situação mais afundo além dos gestores, foram pesquisados documentos importantes que embasam criteriosamente as medidas de segurança para docentes e discentes neste cenário, como a plataforma do MEC, que estabeleceu o ensino remoto como medida educativa emergencial e o parecer do CEE/CE, que contribuiu congruentemente com as decisões do / MEC enquanto durarem os riscos de infecção.

Assim sendo, foi possível cumprir com os objetivos propostos neste trabalho, uma vez que buscou-se investigar o trabalho dos gestores de uma determinada escola particular em Araripe-Ce e entender este trabalho como objetivo específico.

Portanto, considera-se que o trabalho do gestor é fundamental nas atividades escolares e na rotina da instituição como um todo, pois é este profissional que delibera, colabora, organiza e desenvolve propostas que priorizam as boas relações e o desenvolvimento efetivo de práticas preconizadas pelo currículo escolar, principalmente no contexto da pandemia.

\section{REFERÊNCIAS}

ALVES, Gabriel Cunha. Desafios da gestão escolar frente à pandemia de Covid-rig. Educação Pública, v. 20, $\mathrm{n}^{\mathrm{O}}$ 33, $\mathrm{I}$ de setembro de 2020. Disponível em: https://educacaopublica.cecierj.edu.br/artigos/20/33/desafios-da-gestao-escolar-frente-apandemia-de-covid-is

Conselho Estadual de Educação, CEE/CE. BRASIL. Parecer no: 0205/2020, aprovado em: 22/o7/2020. Disponível em: https://www.cee.ce.gov.br/wpcontent/uploads/sites/49/2020/03/Parecer-n\%C2\%BA-0205.2020-Sistema-de-Ensino-doEstado-do-Cear\%C3\%AI-REVISADO-23.07.2020.pdf. Acesso em: or de Maio de 202I.

ELY, Débora. Aulas presenciais nas escolas do RS não têm prazo para retorno. GAÚCHAZH, Porto Alegre, 29 abr. 2020. Disponível em: https://gauchazh.clicrbs.com.br/educacao-e-emprego/noticia/2020/o4/aulas-presenciaisnas-escolas-do-rs-nao-tem-prazo-para-retorno-ckglwcmbiooojorjndtzewizr.html. Acesso em: 25 out. de 2020 .

GONSALVES, E. P. Iniciação à pesquisa científica. 3. ed. Campinas: Alínea, 2003. KENSKI, v, m. Aprendizagem mediada pela tecnologia. Revista Diálogo Educacional, Curitiba, v. 4, n.ro, p.47-56, set./dez. 2003.

OGAWA, Mary Natsue, FILIPAK, Sirley Terezinha. A formação do gestor escolar. XI Congresso nacional de educação - Educere, Pontifícia Universidade Católica do Paraná, Curitiba. 2013. Disponível em: https://educere.bruc.com.br/arquivo/pdf2013/8oro_7046.pdf. Acesso em: I5 de Fev. de 2021.

PERES, Maria Regina. Novos desafios da gestão escolar e de sala de aula em tempos de pandemia. Revista Administração Educacional - CE - UFPE Recife-PE, V.II N. I p. 20-3I, jan-jun/2020.

Disponível

em: 
https://periodicos.ufpe.br/revistas/ADED/article/view/246o89. Acesso em: 19 de dez. 2020.

RODRIGUES, A. (2020). Ensino remoto na Educação Superior: desafios e conquistas em tempos de pandemia. SBC Horizontes, jun. ISSN 2175-9235. Disponível em: http://horizontes.sbc.org.br/index.php/2020/o6/ensino-remoto-na-educacao-superior/. Acesso em: i4 de dez. de 2020.

SARAIVA, K; TRAVERSSINI, C; LOCKMANN, K. A educação em tempos de COVIDI9: ensino remoto e exaustão docente. Práxis Educativa, Ponta Grossa, v. I5, e2016289, p. I24, 2020Disponível em: https://www.revistas2.uepg.br/index.php/praxiseducativa. Acesso em: I5 dez. 2020.

UNESCO. UNESCO lança publicação com orientações sobre práticas educacionais abertas durante a pandemia. 26 maio 2020. Disponível em: https://nacoesunidas.org/unescolancapublicacao-com-orientacoes-sobre-praticas-educacionais-abertas-durante-a-pandemia/. Acesso em: 14 de dez. 2020. 